and are easily removable. In this way, there is ready access to all parts of the instrument. Fig. 1 is a view showing the side open, while Fig. 2 illustrates the complete unit ready for operation. It will be noted that the entire assembly is mounted on a truck for easy movement to any part of the building. Since the mass spectrometer is operated completely by alternating current, the only connexions to be made when the unit is in place is one to the A.c. voltage supply and water connexions for cooling the diffusion pumps.

In addition to the features of compactness, ease of operation and portability, the design permits ready shipment from one place to another, since all the component units may be removed in a short time from the main assembly. As an illustration, the first apparatus of this design was sent from Pittsburgh to New York (400 miles), operated in New York for a week and then returned to Pittsburgh without mishap and with very little trouble.

1 Barber, Proc. Leeds Phil. Soc., 2, 427 (1933).

2 Stephens and Hughes, Phys. Rev., 45, 123 (1934).

Stephens, Phys. Rev., 45, 513 (1934).

- Bainbridge and Jordan, Phys. Rev., 50, 282 (1936).

Nier, Rev. Sci. Inst., 11, 212 (1940).

\section{CARE OF WORKS OF ART IN WAR-TIME}

\section{By F. IAN G. RAWLINS}

$\mathrm{B}^{\mathrm{r}}$ $Y$ 'care' in normal times is probably understood due conservation and maintenance; this in fact is the elemental work which devolves upon curators of any collection of works of art. In times like the present, however, two novel aspects appear : one is protection against enemy action, and the other-a kind of dependent variable-is the greatly increased difficulty of ensuring proper care (in the usual sense) which the necessity for such protection tends to bring about. In other words, there is a distinct possibility of devising excellent 'cover' but at the same time exposing the treasures to such risks of damage and deterioration by inadequate transport and storage arrangements, that the verdict of posterity may well be, "If only they had been left where they were.

This is not merely to seek a nice balance in policy : sooner or later-perhaps sooner-a decision will have become vital; and if, as this article assumes, the plan amounts in effect to evacuation, then it is not a matter to be taken lightly. The hazards may indeed be severe. However, it is by no means my intention to make too much of them. Many can be overcome, and have in fact been overcome. But they are always there, and for the most part, experience to cope with them is not very extensive.

Clearly, evacuation is unjustifiable unless it is reasonably certain that the sum total of the chances of destruction (not only those due to hostilities) is thereby definitely reduced. There are, broadly, two alternatives: (1) dispersal, (2) deep shelters, for example, quarries, tunnels and so forth. The former amounts in practice to the use of country houses as repositories, sending a comparatively small number of objects to each; the latter is more drastic and will probably end in putting the whole collection underground in one place. Which of these methods is chosen will naturally depend upon considerations outside the scope of this contribution. The intention now is to discuss ways and means of securing a tolerable exile.

\section{Dispersal}

Technically, private houses, public halls and buildings of that category present a number of complexities, which make it most important to examine them in detail beforehand. For example, the flooding of basements (otherwise promising storages) is sometimes to be apprehended. The fire risk is usually considerable; appliances will almost certainly need augmenting. Moreover, for books and pictures especially, if the only way of dealing with an outbreak is by water, the curator may even be well advised to avoid the scheme altogether, since the damage suffered would probably be almost irreparable. Generally, the only effective safeguard is to have staff always available for instant salvage in case of fire. This implies the availability of a spare 'sanctuary'. The possible presence of dry-rot in timber floors should not be overlooked. In many instances woodwork can be adequately protected in occupied premises against mould growth and from becoming infested by bacteria by the application of a 10 per cent solution of copper naphthenate in paraffin. Fireproof paint or solution should be applied where desirable, both to wood and to any hangings or curtains used to exclude draughts or to form parts of air-locks. The majority of precious objects are most unlikely to be injured by war gases in vapour form. Splashes of the liquid, however, are almost sure to be fatal on books, manuscripts, pictures and textiles. 'Cellophane', oilskins, rubber fabrics, decreasing in effectiveness in that order, form reasonably sound protective coverings.

The most important factors of all are likely to be temperature and relative humidity (R.H.). It is usually considered that most museum materials and exhibits are well provided for at a temperature of $60^{\circ} \mathrm{F}$. and 60 per cent relative R.H. Research on this subject is as yet insufficient to enable exact figures to be stated, but there is some reason to suspect that the traditional values of $60^{\circ} \mathrm{F}$. and 60 per cent R.H. have been accepted more on account of the comfort of visitors to galleries than on behalf of the contents. While temperature per se is not of the greatest moment, relative humidity assuredly is. It seems likely that a range of between 50 and 55 per cent at around $60^{\circ} \mathrm{F}$. is nearly ideal. Fluctuations in relative humidity such as commonly occur in most buildings at certain seasons of the year are most undesirable. They may produce strains leading to complete breakdown in some pictures (panels in particular), and to a lesser extent with other objects.

The control of relative humidity in war-time storages is exceedingly difficult; so much so indeed as to constitute a major problem. Obviously, fairly simple measures, capable of being implemented more or less on the spot, are all that can be reasonably expected. The main question is how to combine adequate ventilation with satisfactory constancy of relative humidity without elaborate machinery. It is easy enough to install some electric (preferably tubular) heating in a store room, and even to maintain an approximately level temperature, piercing doors or partitions to gain free air-circulation. But it will usually be found that the relative humidity varies over very wide limits, simply repeating the day and night changes that occur outside. The 
range may well be between 40 and 70 per cent or more. These are definitely dangerous limits.

In my experience there is only one course to adopt, and that to some degree at variance with customary methods. It is to seal off the storage chamber as effectively as possible from external influences, by stopping up doors, windows and cracks, and by hanging up heavy felt or similar material. Then small electric fans can be used, suitably orientated, to stir up the air inside the storage chamber itself. Fresh air can, of course, be admitted, when weather conditions are favourable, for a short time. Given reasonable heating, the relative humidity should be roughly constant. That is one point gained. If it settles down to a figure unduly high, say above 65 per cent (see later for the significance of this) more well-dried fabric may be introduced, or the temperature raised, so long as it does not in general exceed $70^{\circ} \mathrm{F}$. If the relative humidity is too low, the temperature may be lowered a little, and wetted material suspended. It is probably prudent to avoid chemical drying agents like calcium chloride or phosphorus pentoxide in the same room as valuable objects. It will doubtless be noticed that the more hygroscopic material there is in the chamber the less sensitive does it become to abrupt changes of relative humidity.

Wherein this treatment differs from that commonly envisaged is its insistence upon constancy of relative humidity even at the expense of 'proper' ventilation. Naturally, if reasonable freedom from fluctuations in relative humidity can be obtained with air-flow from outside, so much the better ; it appears, however, to be a most unlikely state of affairs to find (or even to attain) in war-time quarters.

Instrumentation may well be on a simple scale. Thermostats can be efficient for temperature control, but some method of testing the relative humidity regularly is essential. A psychrometer, or whirling hygrometer, is the obvious way, though recording instruments are useful adjuncts if periodically checked. At least they show the general trend.

\section{Deep Shelters}

These are inevitably in the nature of a long-term policy, and probably out of the question for the majority of institutions and private owners. Nevertheless, they are of great importance, and of considerable scientific interest. Clearly, no perishable material of value can be stored in quarries, caves, tunnels and such-like places without elaborate preparations on the site. The chief enemy is damp; the fire-risk, on the other hand, should be diminished compared with that for isolated houses. Other hazards, less obvious perhaps but sometimes no less severe on that account, are flooding, noxious vapours and gases, dust and falls of roof. These points are excluded from further discussion, since any proposed underground repository where such dangers exist would naturally be rejected out of hand.

We are left, therefore, with the ever-present problem of temperature and humidity control. One favourable factor may be expected to appear immediately, namely, that in many subterranean workings the temperature is approximately constant throughout the year; but the relative humidity may be high - around 90 per cent-and fairly even. Thus, it will be necessary either to erect buildings inside, or to block off suitable portions of the space and to 'condition' them as effectively as may be needed.
Which method is adopted will depend largely upon the type of rock strata involved, and to some extent upon the shape and general lay-out of the place. The class of material to be stored will also weigh. If the natural temperature is low enough (around $45^{\circ} \mathrm{F}$.), it may be possible to obtain the relative humidity required, say, 55 per cent at $60^{\circ} \mathrm{F}$., by straightforward temperature control alone, without recourse to refrigeration, except perhaps temporarily, to hasten the process of drying out. If this is so, and electric power is available, as it supposedly would be in many cases - the project becomes quite tractable. In fact, conditions approaching the ideal can be realized relatively simply, given sound initial equipment and constant supervision. A stand-by generating plant in case of power failure is, of course, essential

Repositories of this kind represent a type of scheme 'easier said than done', however ; difficulties of a somewhat crude nature are apt to appear very early in the proceedings. One is often that of access, both to the site itself and to portions of it below ground which theoretically are the most advantageous to occupy. It should always be borne in mind that priceless and irreplaceable things are to be brought there (since such a plan would never be contemplated for minor exhibits), unloaded and perhaps unpacked, put in place and duly invigilated. In addition to which it may be necessary to allow for objects of great bulk combined with excessive fragility-altogether not an enterprise to be embarked upon toó lightheartedly. A good feature awaiting us, however, is that quarry - and some other-adits are often far from straight, which is a great advantage in forming natural baffles against the propagation of blast.

\section{General}

There remain a few general considerations common to any programme of evacuation and war-time storage of valuables and perishable objects. One is that of avoiding the growth of mould or mildew. A relative humidity so low as 68 per cent has been found to permit of mould growth, especially at temperatures around $70^{\circ} \mathrm{F}$., showing that raising the temperature is not in itself any security, if the relative humidity remains excessive. Good ventilation, or at least adequate air-movement, is a safeguard. Another matter concerns lighting. Some illumination is desirable as a check upon mould growth itself. In addition, for pictures less than about fifty years old, there is a tendency for the medium to turn yellow, especially if of a 'fat' nature. This process is favoured by darkness. For older paintings, oxidation is probably complete, and no colour change need be expected as the result of storage away from light, so far as the medium is concerned. Water colours and miniatures should always be stored away from light. Where possible, objects should be unpacked to facilitate inspection, and to give the best chance of air circulation.

Generally, there can scarcely be hard and fast rules, except perhaps to recollect that flooding, exposure to excessive relative humidity, attacks of mildew and-no less-inadequate or rough transport may bring about damage amounting almost to disaster. None of these things should stand in the way of seeking the safest place for works of art. But 'watch and ward' was never more urgent.

Some scattered literature on the subject began to accumulate as the result of the Spanish Civil War. 
Since then two valuable contributions have appeared : (1) "Air-Raid Precautions in Museums, Picture Galleries and Libraries" (British Museum Trustees, 1939) and (2) "Preservation of Paintings in War. Time" by G. L. Stout (Fogg Art Museum, Harvard University, U.S.A., 1942). Meanwhile, data are being assembled from day to day as the result of experience in war-time repositories. Much of it would never have been obtained in years of peace. Some of it will doubtless be significant for future planning of museums and galleries.

\section{O BITUARIES}

\section{Sir Daniel Hall, K.C.B., F.R.S.}

Sir Daniel Hall-long known simply as A. D. Hall-had an unusually wide circle of friends who will deeply mourn his death on July 5 at a nursing home in London.

$\mathrm{He}$ was born at Rochdale on June 22, 1864, and was educated at the Manchester Grammar School, where he already showed wide scientific interests and was equally keen on chemistry, physics and the field sciences, botany and geology. From Manchester he gained the Brackenbury Science Scholarship to Oxford and entered Balliol College in 1881. Here he was soon recognized as possessing entirely exceptional qualities and he lived a very full life. At no time was he a narrow specialist, least of all during these formative years at Oxford. Everything he touched he did well, whether it were science, athletics, or participation in the various movements then forming part of Oxford life. He rowed in the Balliol eight and he laid the foundations for those wide intellectual and artistic tastes which characterized him throughout his life and added so much to his personal charm. At Oxford, too, he was fortunate in his choice of friends, many of whom afterwards had distinguished careers. He did not remain at Oxford, but left in 1884 to become a science master at King Edward VI Grammar School, Birmingham, where he met his first wife, Mary Brookes, and wrote his first book, a little text-book for the use of his students. He soon gave up school teaching and for a time served as lecturer in the university extension movement then beginning; Kent and Surrey were his counties; they were then more rural than now. Here he became interested in agricultural education and he soon saw that if it was to be effective it must be systematic and continuous; occasional lectures were quite inadequate. $\mathrm{He}$ was able to persuade a very public-spirited gentleman, F. J. Halsey, of the soundness of his views, and $\mathbf{M r}$. Halsey saw that funds were provided for establishing an agricultural college. Hall knew the two counties well, and selected the old Latin school at Wye as the proper place; it was a medieval foundation with attractive old buildings that gave the setting he always liked so much. $\mathrm{He}$ took possession in 1894 and was able to add laboratories and new buildings without doing violence to the old ones.

Hall was ably supported by a group of able men : F. B. Smith, J. Percival, F. Theobald, T. R. Robinson and H. H. Cousins, and between them they worked out systematic courses on agricultural science and practice, and trained numbers of young men who afterwards held very important posts at home and abroad. Hall insisted that the teaching must not only be based on sound science but must also con- stitute a new science, always drawing on practical agriculture for its materials and its illustrations. $\mathbf{H e}$ set the example by becoming a first-class grower of fruit, hops and flowers, especially roses, tulips and sweet peas; he could hold his own with any expert, and the farmers and gardeners of Kent quickly recognized him as a fellow-craftsman of outstanding distinction. He was equally successful in dealing with farmers; he was a remarkably shrewd observer and could quickly detect the flaw in management which had led to some unsatisfactory condition of crops or animals. The early prejudice against agricultural education could not stand up against ability of this sort, and before long the high position of $\mathrm{Wye}$ was assured.

Hall always recognized, however, that both the teaching and the advisory work then beginning to develop were limited by the amount and value of the science on which they were based, and very soon this began to be insufficient. There was at that time no provision for research; education was supposed by the administration to be a proper object for State aid, but not research, which was regarded as something entirely distinct and unrelated. Hall set him. self to remedy this defect; he gave up Wye at the height of its success and in 1902 went to Rothamsted in succession to Gilbert; he found the whole place moribund, but with characteristic energy and devotion proceeded to put new life into it. He had neither staff, apparatus nor funds and was snubbed by the Board of Agriculture when he asked for a grant, yet his infectious enthusiasm attracted first men then money, until finally he had built up a compact team of research workers who opened lines of investigation that have since proved very fruitful. The Goldsmiths Company gave a handsome endowment for soil research and this lead has been followed by a long line of generous supporters.

Once again, however, Hall felt impelled to give up the work when he had got it well on the road to success. In $1909 \mathrm{Mr}$. Lloyd George set up the Development Fund for the purpose of developing agriculture and improving rural life, and he appointed a small Commission, including Hall, to administer it. Hall soon became the dominating figure and in October 1912 was induced to give up Rothamsted so as to devote his whole time and energy to the work. 'The full story has not yet been written, and reference can be made here only to that part dealing with research and education. It was agreed that agricultural research was to be greatly developed. Two methods were possible : the establishment of a large central research station covering all branches of agriculture on the model of the United States Department of Agriculture at Washington; or a number of smaller stations attached to the universities, where different branches of agriculture or agricultural science would be studied. The latter method was chosen, and there is no question that the decision was sound. Agricultural science has developed remarkably well in Great Britain as the result of the freedom conferred by the new arrangements, which were indeed the envy of scientific workers from other countries when they came over here. A very effective advisory service was also set up and the educational machine was greatly improved. Later experience has shown that these three services could well have been more closely linked, but there is no evidence that Hall was responsible for that defect. $\mathrm{He}$ certainly achiever a great amount of most useful constructive work. 